\title{
Guía para autores
}

\section{GUIDELINES FOR AUTHORS}

\section{DIRETRIZES PARA AUTORES}

\section{Versión 2017}

Perspectiva Geográfica es una revista académica arbitrada especializada en estudios geográficos y de planificación territorial dirigida a comunidades académicas, investigativas y del desarrollo territorial, interesadas en temas geográficos y ciencias afines. La publicación es editada desde 1987 por el programa de Estudios de Posgrado en Geografía (EPG) en el marco del convenio de colaboración científica entre la Universidad Pedagógica y Tecnológica de Colombia (UPTC) y el Instituto Geográfico Agustín Codazzi (IGAC); a partir del 2013, las publicaciones se realizan semestralmente.

En la revista se publican artículos originales e inéditos de investigación, reflexión y revisión, referidos a la espacialidad de los fenómenos sociales, económicos, políticos, culturales y naturales, desde diversas perspectivas y enfoques teóricos. También acoge los estudios sobre aspectos técnicos y metodológicos del quehacer propio de los geógrafos, así como los trabajos de geografía aplicada en los campos de la geomática, la planificación territorial y las investigaciones de frontera.

Los posibles autores de Perspectiva Geográfica deben abstenerse de postular simultáneamente sus contribuciones académicas a otras publicaciones y adaptar los manuscritos a las especificaciones que se describen en el apartado de Aspectos formales de esta guía. El Open Journal System (OJS) de la revista, que puede ser consultado a través de la página web http://revistas.uptc.edu. co/, está habilitado para recibir los archivos, así como el correo electrónico perspectiva.geografica@uptc.edu.co; por este medio debe detallarse la información de contacto del autor o autores. La recepción de artículos está sujeta a las convocatorias programadas por la revista.

\section{Arbitraje}

Los artículos son evaluados, inicialmente, por el equipo editorial; en esta primera etapa se determina la pertinencia de la temática y la calidad editorial del artículo. Finalizada esta evaluación, las contribuciones son sometidas a arbitraje en la modalidad de doble ciego, con lo que se asegura la confidencialidad y el anonimato tanto de autores como de árbitros, y la imparcialidad en el arbitraje. El Comité Editorial selecciona árbitros nacionales e internacionales, principalmente externos al programa de Estudios de Posgrado en Geografía (EPG), por su trayectoria investigativa relacionada con los temas de los artículos. 
Los árbitros están encargados de evaluar en cada documento aspectos formales, metodológicos y conceptuales con el fin de garantizar la rigurosidad científica. Estos podrán recomendar publicar el artículo, publicar el artículo con correcciones o rechazar el artículo. En caso de que un par recomiende la publicación y otro la rechace, se buscará el concepto de un tercer árbitro para que resuelva el empate. Si la recomendación es publicar el artículo con correcciones, una vez realizadas por el autor, el documento se enviará nuevamente al árbitro para verificarlas. Cuando se obtienen los resultados del arbitraje, el Comité Editorial comunicará al autor la decisión tomada sobre el artículo y los pasos a seguir según los resultados. Este proceso dura, en promedio, seis (6) meses. Sin embargo, este periodo puede verse afectado según la disponibilidad de los árbitros y otros factores que incidan sobre el tratamiento de los artículos.

Una vez que los documentos son aceptados, se entiende que el autor o autores ceden a la revista Perspectiva Geográfica los derechos patrimoniales, esto quiere decir que autorizan la publicación del artículo en cualquier formato o medio. Estos se divulgarán en directorios, bases de datos y sistemas de indexación. La publicación y la evaluación de los artículos no tiene ningún tipo de remuneración.

\section{Tipología de los artículos:}

Basados en los parámetros de Colciencias, los artículos pueden clasificarse según los siguientes tipos:

Artículo de investigación científica y tecnológica. Documento que presenta, de manera detallada, los resultados originales de proyectos de investigación. La estructura generalmente utilizada contiene cuatro apartes importantes: introducción, metodología, resultados y conclusiones.

Artículo de reflexión. Documento que presenta resultados de investigación desde una perspectiva analítica, interpretativa o crítica del autor, sobre un tema específico, recurriendo a fuentes originales.

Artículo de revisión. Documento resultado de una investigación, en el que se analizan, sistematizan e integran los resultados de investigaciones publicadas o no publicadas, sobre un campo en ciencia o tecnología, con el fin de dar cuenta de los avances y las tendencias de desarrollo. Se caracteriza por presentar una cuidadosa revisión bibliográfica de por lo menos 50 referencias.

\section{Aspectos formales}

Los artículos deberán presentarse en hoja tamaño carta, interlineado a espacio y medio, con márgenes de $3 \mathrm{~cm}$, en letra Times New Roman de 12 puntos; la

1 Tomado de: http://publindex.colciencias.gov.co:8084/publindex/docs/informacionCompleta. pdf 
extensión total no debe exceder las 20 páginas. El archivo debe ser enviado en formato .docx o .rtf a través de correo electrónico o del OJS de la revista.

\section{Estructura}

El documento, según el tipo de artículo que sea, debe contener la siguiente información:

\section{Página titular}

Título del artículo en español y en inglés (máximo 20 palabras), información de contacto del autor (nombre, último título obtenido e institución que lo otorgó, afiliación institucional, correo electrónico, título del proyecto y el grupo de investigación del cual se origina el artículo, así como el ente financiador del proyecto, en caso de que lo haya), resumen y abstract (máximo 150 palabras), palabras clave y keywords (máximo siete, en orden alfabético, reconocidas en tesauros).

\section{Texto}

Si el artículo es de investigación: introducción (presentación general del estudio o del tema tratado, incluyendo el problema, los fundamentos teóricos que le dieron soporte al estudio, los objetivos e hipótesis), metodología (incluir información del área de estudio, de ser pertinente), resultados y discusión, conclusiones (debe contener la síntesis de los principales resultados y del aporte a la solución del problema) y referencias.

Si el artículo es de reflexión o de revisión: introducción (presentación general del estudio o del tema tratado, incluyendo el problema, los fundamentos teóricos que le dieron soporte al estudio, los objetivos e hipótesis, en caso de existir), desarrollo y discusión, conclusiones (debe contener la síntesis de los principales resultados y del aporte a la solución del problema) y referencias.

Para palabras en idiomas distintos al castellano se deben emplear cursiva; para las cifras, los números miles se separan con puntos, y los decimales, con coma. Por ejemplo: 1.202,7. Los años no llevan punto por no ser cifras. Las cifras con números enteros hasta quince se escriben con palabra. Deben utilizarse abreviaturas, en los casos que correspondan; se debe dejar un espacio entre el número y el símbolo o abreviatura. Se debe usar subíndice y superíndice según el caso.

\section{Figuras y tablas}

Todas las ilustraciones, incluyendo fotos, diagramas, mapas y gráficas, se denominan y referencian como figuras, la primera letra en mayúscula inicial (Figura, Tabla). Tanto las tablas como las figuras deben citarse en el texto y numerarse en orden de aparición en el mismo. El título de las figuras deberá ir en la parte inferior de las mismas y el de las tablas, en la parte superior. Los mapas deberán contener título, fecha, leyenda, sistema de coordenadas, escala, norte y fuente de datos o autor. Las tablas y figuras deben estar ubicadas lo 
más próximo a la referencia indicada en el texto y centrarse en los márgenes. Cada figura debe entregarse en una carpeta aparte en formato JPG, TIFF o GIF (superior a $300 \mathrm{dpi}$ ).

\section{Sistema de citación y referencias bibliográficas}

El sistema de citación y de referencias adoptado por la revista Perspectiva Geográfica es el de la American Psychological Association (APA). En este sistema, las referencias se hacen en el cuerpo del texto anotando el apellido del autor seguido del año de publicación entre paréntesis y, en citas textuales, las páginas consultadas. En caso de que se cite más de una obra de un autor del mismo año, deberá adicionarse una letra para identificar a cuál se hace referencia. Ejemplos:

(Prats, 2005)

(Prats, 2005a)

(Prats, 2005, p. 15)

La lista de referencias debe presentarse en orden alfabético según los siguientes ejemplos:

Libro

Vallés, J.M. (2004). Ciencia Política. Una introducción. Barcelona, España: Ariel.

Capítulo de libro

Prats, J. (2005). Modos de gobernación de las sociedades globales. En Cerri1lo, A. (Coord.), La gobernanza hoy: 10 textos de referencia (pp. 145-172). Madrid, España: INAP.

Artículo de revista

Rivera, L. (2014). Factores de territorialización para la gestión del desastre del casco urbano de Gramalote, Norte de Santander 2010-2013. Perspectiva Geográfica, 19(1), 11-28.

Tesis

Ramírez, L. (2013). ¿Irse, quedarse o llevar el territorio a cuestas? El proceso de reorganización territorial Nasa después del terremoto de 1994 en Tierradentro, Cauca (tesis de maestría en Geografía Humana). Universidad de los Andes, Bogotá. 